\title{
Physico-Chemical Characterization of Slag Waste Coming From IGCC Thermal Power Plant
}

\author{
A. Acosta, M. Aineto and I. Iglesias \\ Laboratory of Applied Mineralogy, Universidad de Castilla-La Mancha, Ciudad Real, \\ Spain
}

M. Romero and J.Ma. Rincón ${ }^{1}$

The Glass-Ceramics Laboratory, Instituto Eduardo Torroja de Ciencias de la Construcción, CSIC, Madrid, Spain

\begin{abstract}
The new gas installations of combined cycle (GICC) thermal power plants for production of electricity are more efficient than conventional thermal power plants, but they produce a high quantity of wastes in the form of slags and fly ashes. Nowadays, these by-products are stored within the production plants with, until now, no applications of recycling in other industrial processes. In order to evaluate the capability of these products for recycling in glass and ceramics inductory, an investigation for the full characterization has been made by usual physico-chemical methods such as chemical analysis, mineralogical analysis by XRD, granulometry, BET, DTA/TG, heating microscopy and SEM/EDX.
\end{abstract}

Keywords: IGCC, slag, industrial waste, characterization, recycling

\section{Introduction}

Gas installations of combined cycle (GICC) process are a fully different electrical power production process with energy obtained from burning a mixture of coal and coke coming from petroleum refining. In this new process, inorganic wastes are produced as fly ashes and slag residual material. GICC technology is based on a coal gasification process, namely, the conversion of coal into combustible gas, which is then subjected to an exhaustive cleaning process [1]. The result is a synthetic gas virtually free of pollutants, which can be burned with high efficiency in a combined-cycle electricity-generating unit. The gross energy efficiency of this power plant is $47.12 \%$, while the net efficiency reaches $42.5 \%$ [2]

A solid waste is obtained in the form of a vitrified slag not soluble in water, and therefore, the use or storage presents no environmental problems. The sulphur is recovered in elementary form and is therefore suitable as marketing product. This is not the case of slag, which until now is not recycled to other industrial processes to be eventually used as secondary raw material. This slag waste is produced in a quantity of 100,000 ton/years in the only one plant existing in Spain at this moment in working operation. This plant has been the second installed production in Europe [ $\underline{3}$ and $\underline{4}]$. 
Nowadays, this waste is being used as filling mining material. With respect to its composition, this waste is unique as inorganic residue and is not related to other slags obtained in conventional thermal power plants. Due to the intrinsic nature of the GICC process, this new type of power plant gives rise to a huge amount of slag with respect to the fly ash produced in the same plant. Until now, it never has been proposed as candidate for recycling as secondary raw material in other industries. Nevertheless, since 1996, some European research projects have been carried out in the CECA Programme [ $\underline{5}$ and $\underline{6}]$. On the other hand, recently, similar inorganic industrial wastes have been investigated for production of new glasses and glass-ceramics [7]. Recycling as glasses and glass-ceramics of industrial wastes is being considered recently as a possibility for inertization and production of new materials []․

The aim of this paper is to show the full characterization of the slag waste produced in the Spanish power GICC plant in order to explore the capabilities of this industrial residue for the ceramics and glass production.

\section{Materials and Methods}

The GICC slag here considered comes from an industrial plant (ELCOGAS SA) recently implemented and working in Puertollano, Ciudad Real province, Spain [3]. Usual methods for characterization of materials were used, such as: XRF fluorescence for chemical analysis; XRD for mineralogical characterization; granulometric analysis (mesh grids); specific surface (BET nitrogen absorption method) thermal methods, such as DTA/TG analysis, melting behaviour and relative viscosity variation at high temperature by HSM (hot stage microscopy) microstructure and microanalysis by $\mathrm{SEM} / \mathrm{EDX}$.

Table 1 shows several analysis carried out during 1999 from several and continuous sampling of production. It can be seen that standard deviation of components is not high and main elements expressed as oxides are: $\mathrm{SiO}_{2}, \mathrm{Al}_{2} \mathrm{O}_{3}, \mathrm{Fe}_{2} \mathrm{O}_{3}, \mathrm{MnO}, \mathrm{MgO}, \mathrm{CaO}$, $\mathrm{Na}_{2} \mathrm{O}, \mathrm{K}_{2} \mathrm{O}, \mathrm{TiO}_{2}, \mathrm{P}_{2} \mathrm{O}_{5}$ and $\mathrm{SO}_{3}$.

\section{Table 1. Major elements determined by XRF in several IGCC slags}

\begin{tabular}{||c|c|c|c|c|c|c|c|c|c|c|c|c|c|c|c||}
\hline \hline$(\%)$ & E-1 & E-2 & E-3 & E-4 & E-5 & E-6 & E-7 & E-8 & E-9 & E-10 & E-11 & E-12 & E-13 & Average & $\sigma^{2}$ \\
\hline $\mathrm{SiO}_{2}$ & 58.25 & 59.83 & 54.96 & 58.15 & 58.10 & 53.54 & 55.75 & 51.90 & 54.00 & 55.91 & 57.27 & 60.32 & 59.49 & 56.7 & 2.6 \\
\hline $\mathrm{Al}_{2} \mathrm{O}_{3}$ & 19.00 & 19.31 & 19.55 & 19.71 & 19.95 & 22.25 & 24.05 & 23.48 & 21.59 & 26.14 & 23.01 & 21.91 & 23.26 & 21.8 & 2.2 \\
\hline $\mathrm{Fe}_{2} \mathrm{O}_{3}$ & 4.26 & 4.47 & 4.10 & 4.45 & 4.43 & 5.58 & 5.25 & 4.85 & 5.24 & 5.72 & 5.67 & 4.28 & 4.50 & 4.8 & 0.6 \\
\hline $\mathrm{MnO}$ & 0.05 & 0.05 & 0.05 & 0.05 & 0.05 & 0.06 & 0.05 & 0.06 & 0.06 & 0.06 & 0.06 & 0.04 & 0.04 & 0.1 & 0.0 \\
\hline $\mathrm{MgO}$ & 0.95 & 1.04 & 0.92 & 1.01 & 1.00 & 1.11 & 1.09 & 1.05 & 1.13 & 1.07 & 1.07 & 0.80 & 0.84 & 1.0 & 0.1 \\
\hline $\mathrm{CaO}$ & 11.23 & 11.78 & 10.73 & 11.16 & 11.19 & 11.15 & 9.93 & 10.03 & 5.44 & 6.95 & 8.39 & 6.56 & 6.25 & 9.3 & 2.3 \\
\hline $\mathrm{Na}_{2} \mathrm{O}$ & 0.40 & 0.40 & 0.29 & 0.38 & 0.38 & 0.34 & 0.37 & 0.28 & 0.32 & 0.31 & 0.27 & 0.24 & 0.27 & 0.3 & 0.1 \\
\hline $\mathrm{K}_{2} \mathrm{O}$ & 1.98 & 2.00 & 1.50 & 2.00 & 2.02 & 1.73 & 2.22 & 2.33 & 2.21 & 2.26 & 2.36 & 2.29 & 2.36 & 2.1 & 0.3 \\
\hline $\mathrm{TiO}_{2}$ & 0.48 & 0.48 & 0.47 & 0.50 & 0.50 & 0.57 & 0.62 & 0.60 & 0.57 & 0.68 & 0.60 & 0.55 & 0.60 & 0.6 & 0.1 \\
\hline $\mathrm{P}_{2} \mathrm{O}_{5}$ & 0.06 & 0.06 & 0.04 & 0.05 & 0.05 & 0.07 & 0.06 & 0.05 & 0.04 & 0.04 & 0.06 & 0.02 & 0.02 & 0.0 & 0.0 \\
\hline $\mathrm{SO}_{3}$ & 1.60 & 1.40 & 1.70 & 1.50 & 1.40 & 0.95 & 1.20 & 1.25 & 1.88 & 0.75 & 1.48 & 1.25 & 1.30 & 1.4 & 0.3 \\
\hline
\end{tabular}




\begin{tabular}{|l|c|c|c|c|c|c|c|c|c|c|c|c|c|c|c|}
\hline LOI & 2.46 & 0.18 & 4.35 & 1.68 & 1.25 & 4.32 & 1.43 & 3.95 & 7.93 & 0.22 & 1.60 & 3.38 & 2.67 & 2.7 & 2.1 \\
\hline
\end{tabular}

The loss ignition percentage (LOI) and $\mathrm{CaO}$ content are different among samples due to variation of melting additive and operation parameters during production. As is known, these losses come from the unburned raw materials. In principle, the homogeneity in composition along time production allows us to propose this slag as candidate for recycling in several material productions. Therefore, an average sample was taken for full characterization as secondary raw material.

\section{Results and Discussion}

\subsection{General characterization}

Fig. 1 shows the XRD representative diagram of slags wherein their amorphous character is shown. However, some samples, as shown here, depict some spinel peaks in the range of $45^{\circ}$ diffraction angle.

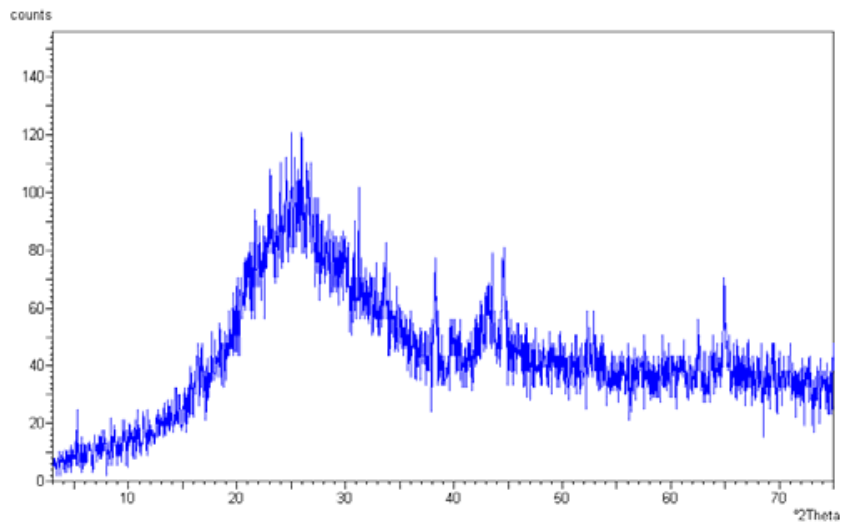

Fig. 1. - XRD diagram of IGCC slag (sample E-11 from Table 1) here investigated

Fig. 2 shows the range of granulometric analysis from slag, here investigated. It can be seen they are lower than $10 \mathrm{~mm}$ with a homogeneous distribution due to milling processing in the plant.

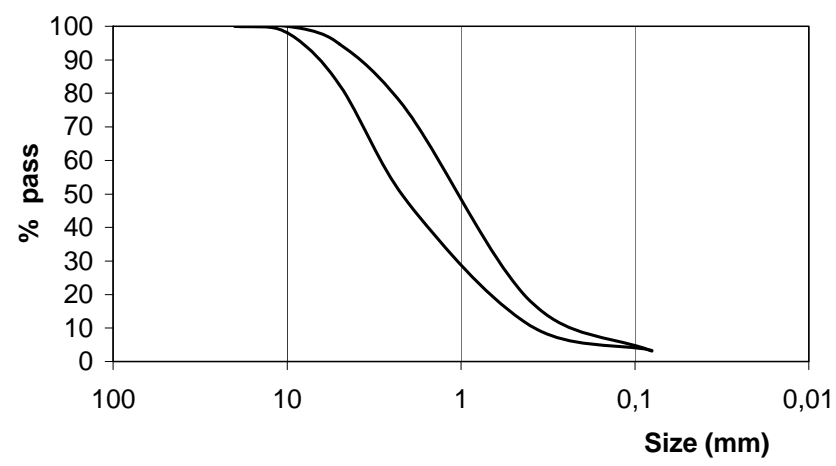

Fig. 2. - Granulometric range curves of IGCC slags. 
The density corresponding to $<50-\mu \mathrm{m}$-sized grains is $2.5857 \mathrm{~g} / \mathrm{cm}^{3}$ and the specific surface is $1.066 \mathrm{~m}^{2} / \mathrm{g}$. Though the specific surface is very low, due may be to high porosity and no compactness of powder, the non-porous character is related to the high vitrification of slag, which can facilitate the melting of this material. In order to see the shape and microstructure of slag particles, they have been examined and analyzed by $\mathrm{SEM} / \mathrm{EDX}$ as will be seen later.

\subsection{Thermal and devitrification behaviour}

With respect to the thermal properties, taken into account in principle due to the chemical composition of capability as ceramic/glasses raw material, a full thermal characterization can be carried out as follows.

Fig. 3 shows the DTA/TG determination where the slag at $30^{\circ} \mathrm{C} / \mathrm{min}$ is a very stable glass because it does not show clear exothermic peaks. The wide endothermic band around $500-550^{\circ} \mathrm{C}$ correspond to the glass transformation temperature as is usual in glasses [9]. Finally, close to $950^{\circ} \mathrm{C}$, there is a small endothermic indicating the starting of melting of this glassy slag. The observation and continuous heating simultaneously in a heating stage microscope (HSM) have allowed the determination of relative viscosity change with temperature (Table 2). As is shown in Fig. 4, this variation is very steep in the $1260-1335^{\circ} \mathrm{C}$ range. This is usual of well-known "short glasses" susceptible to give devitrification at high temperatures [9]. As is known, there is an inverse relation of viscosity of a melt with nucleation and growth of crystalline phases; therefore, lower viscosities imply high tendency of crystallization on these slags. On the other hand, from the variation of viscosity with temperature and relative fluidity range, it can be anticipated the adequacy of this slag as raw material for glass fibre production [10].

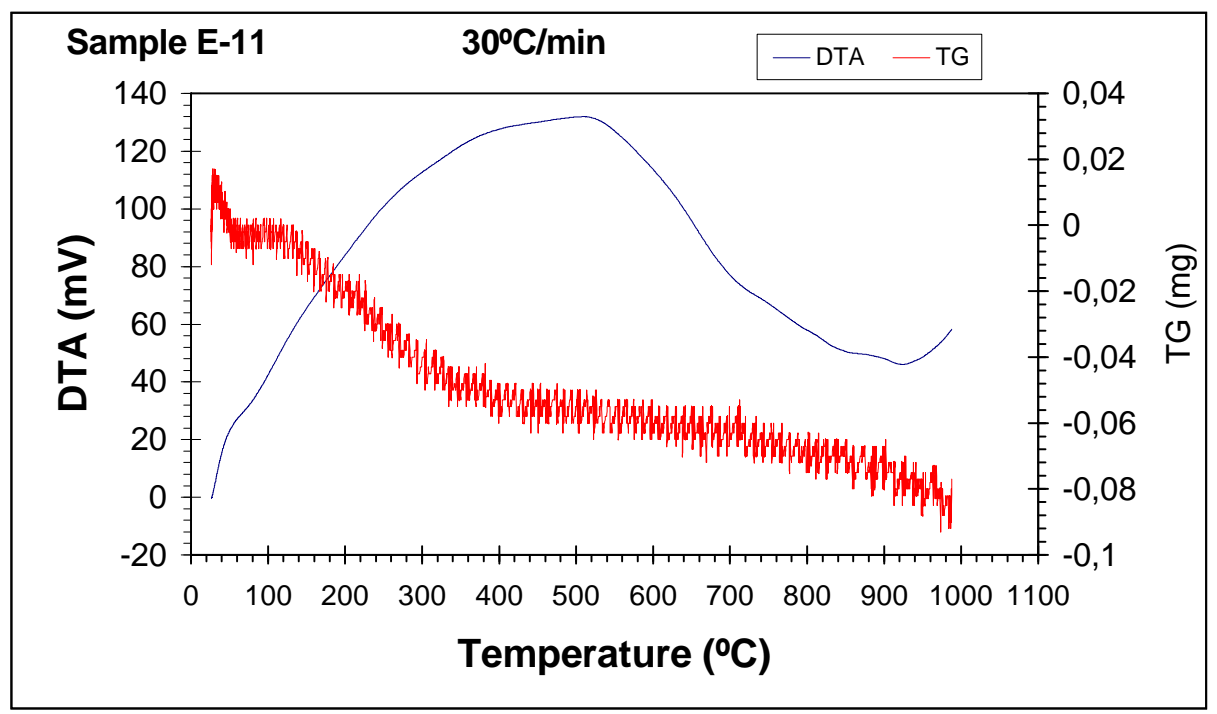

Fig.3.- DTA/TG of E-11 slag sample with $30^{\circ} \mathrm{C} / \mathrm{min}$ heating rate. 


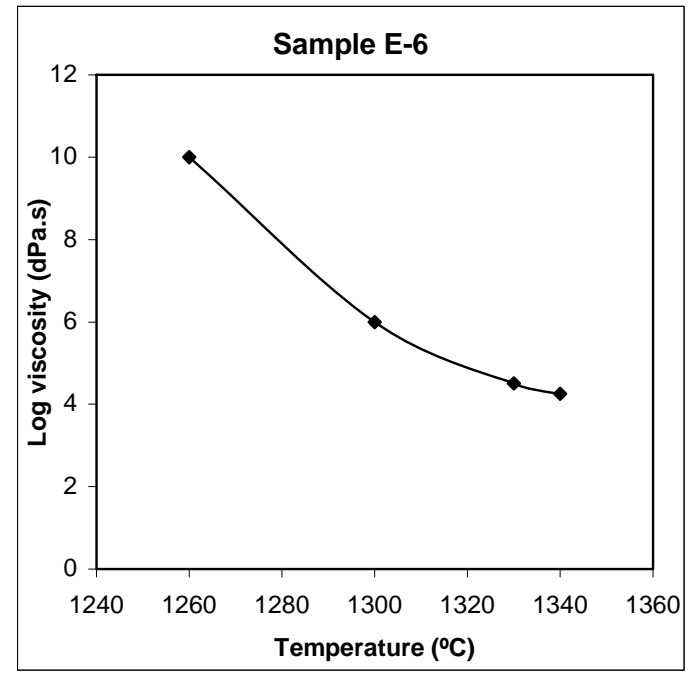

Fig. 4.- HSM from pressed powder sample (sample E-6 from Table I).

Table 2. Fixed points of viscosity determined by HSM in IGCC slag (sample E-6 from Table 1).

\begin{tabular}{|c|c||}
\hline Sample E-6 & $\begin{array}{c}\text { Sample temperature } \\
\text { of transformation } \\
\left({ }^{\circ} \mathrm{C}\right)\end{array}$ \\
\hline Sintering point & 1260 \\
\hline softening & 1300 \\
\hline half sphere & 1330 \\
\hline Fluidity & 1340 \\
\hline
\end{tabular}

\subsection{Microstructure and microanalysis}

Fig. 5 and 6 show general view of particles of different sizes depicting concoidal fractures, smooth surfaces and porous microstructures. In all particles, the edges were very narrow angles, which could facilitate the melting and/or sintering of grains.

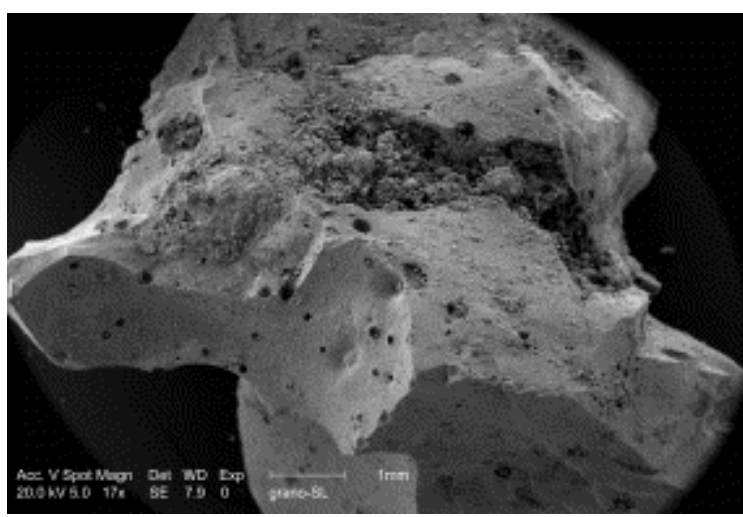

Fig. 5.- SEM micrograph from a grain of slag.

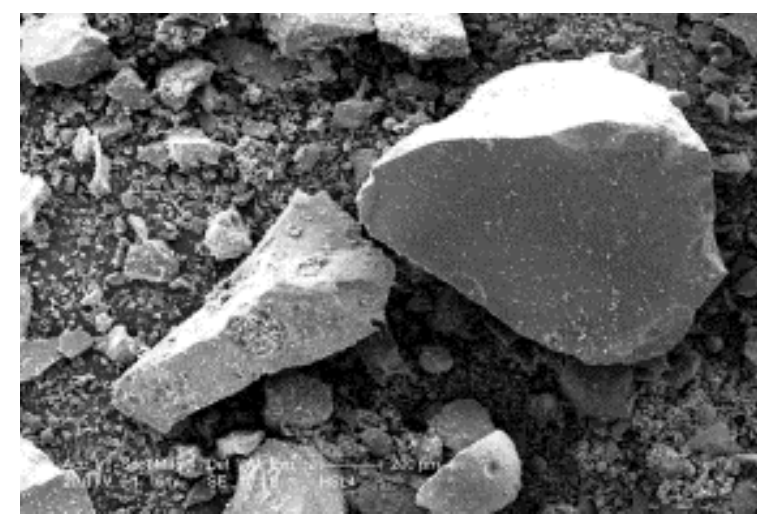

Fig. 6. SEM micrograph from powdered milled slag $(<620 \mu \mathrm{m})$. 
Table III shows the analysis carried out by SEM/EDX from the E-11 slag sample, compared with the average chemical analysis of samples from Table 1.

Table 3. Chemical composition (SEM/EDX) of major elements from E-11 slag sample from Table I compared with average chemical analysis of samples from Table 1.

\begin{tabular}{||c|c|c|c||}
\hline \hline Oxide & $\begin{array}{c}\text { Chemical analysis } \\
\text { (Average Table 1) }\end{array}$ & $\begin{array}{c}\text { SEM/ EDX } \\
(\mathrm{E}-11)\end{array}$ & $\begin{array}{c}\text { Ternary components } \\
\text { (Average Table 1) }\end{array}$ \\
\hline $\mathrm{SiO}_{2}$ & 56.7 & 57.48 & 64.58 \\
\hline $\mathrm{Al}_{2} \mathrm{O}_{3}$ & 21.8 & 23.31 & 24.83 \\
\hline $\mathrm{CaO}$ & 9.3 & 7.62 & 10.59 \\
\hline $\mathrm{Fe}_{2} \mathrm{O}_{3}$ & 4.8 & 7.84 & \\
\hline $\mathrm{K}_{2} \mathrm{O}$ & 2.1 & 1.9 & \\
\hline $\mathrm{MgO}$ & 1.0 & 1.86 & \\
\hline
\end{tabular}

\section{Conclusions}

From the physico-chemical characterization results, it can be concluded that GICC slag can be, in principle, a useful raw material for the production of bulk glasses, glass fibres and glass-ceramics as well as ceramic sintered materials, which is the objective of work now carried out whose results will be given in next papers.

\section{Acknowledgements}

The authors thank ELCOGAS SA of Puertollano, Ciudad Real, Spain, for supporting this research and for giving permission for this publication.

\section{References}

[1] SENDÍN PUENTE. U.: La gasificación del carbón integrada en ciclo combinado para la generación limpia de electricidad European Lecture Series on clean Coal Technologies- THERMIE Programme.

[2] TAKEKMATSU. T. Y MAUDE. C.: Coal Gasification por IGCC power Generation. IEA Coal Research. IEACR/37. March. 1991.

[3] ELCOGAS. IGCC Puertollano Power Plant. Diffusion Brochure.

[4] MENDEZ VIGO. I. (ELCOGAS): Puertollano Plant status and enviromental issues regardin yhe use of petroleum coke en Seminar on "The use of coal in mixture with wastes and residues". Madrid. 1996.

[5] CECA Proyect ESC 7220-DE/072. "Valorization of IGCC power plant by- products as secodary raw materials in construction" (VABYPRO).

[6] CIEMAT-PROGRAMA I+D OCICARBON: Clean Coal Technologies Handbook Section 8: Integrated Gasification Combined Cycle. Ed. Comisión Europea. Directorio General de la Energía s.f. 
[7] J. Ma. Rincón y M. Romero. "Los materiales vitrocerámicos en la construcción". Materiales de construcción. $n^{\circ}$ 242-243 (1996): 91-106.

[8] J. Ma. Rincón. M. Romero y Mª E. Zayas. Técnica Cerámica 3-4 (1994): 220.

[9] J.M. Fernández Navarro. El Vidrio. CSIC. Madrid. 1991.

[10] J.M. Cáceres. J. E. García Hernández. "Caracterización de fibras en forma de lana de roca para aislamientos obtenidas a partir de basaltos canarios". Materiales de Construcción. $\mathrm{n}^{\mathrm{o}}$ 242-243 (1996): 61-78. 